\title{
Subordinate Categories in Ossetian
}

\section{Chermen Gogichev PhD.}

\author{
Associate Professor, Plekhanov Russian University of Economics, Chair of Business Communication
}

Email:chermeengo@yahoo.com

Doi:10.5901/mjss.2015.v6n5s2p197

\begin{abstract}
The article looks at subordinate categories of the class "human" in Ossetian represented in idiom semantics. Various structures subdividing the original category are examined along with cognitive operations underlying the process of subcategorization. The structures termed as categorizing concept and specifying categories appear as the base of a cognitive operation that can be described as "subject (human) - relation (to) - object". The relation component is indicated as to know, be able to, be able to resist and to disdain. The section of object is represented by categories "hardly understandable things", "impossible things" "dangerous things" and "things that can not be taken away" expressing the culturally relevant meaning.
\end{abstract}

Keywords: subordinate categories; idiom semantics; Ossetian; categorization; concept; specifying categories; cognitive operation; subcategorization

\section{Introduction}

The problem of categorization and its impact on the language structure is one of the most important in modern semantics (Talmy 2000). Observations on the process of categorization mainly focus on structures representing the basic level of the conceptual system. The basic level categories are characterized by following properties:

"Perception: Overall perceived shape, single mental image; fast identification.

Function: General motor program.

Communication: Shortest, most commonly used and contextually neutral words, first learned by children and first to enter the lexicon.

Knowledge Organization: Most attributes of category members are stored at this level" (Lakoff 1987).

The process of further categorization involves the basic or superordinate level categories in forming more detailed classes at the subordinate level representing different conceptual dimensions of the basic category (Gogichev 2011). Selection of the conceptualized properties is not arbitrary but defined by cognitive structures that govern the categorization. These cognitive structures can be referred to as concepts seeking representation of different qualities constituting their meaning and categories that can signal the type of relation that the conceptualized entity has to this category.

\section{Literature Review}

The first type categorizing inventory groups together within category structuring system by means of which the original category is extended. Such construction can be accounted for as gestalt structure (in terms of Ehrenfels' and M. Wertheimer's notion): "There are wholes, the behaviour of which is not determined by that of their individual elements, but where the part-processes are themselves determined by the intrinsic nature of the whole. It is the hope of Gestalt theory to determine the nature of such wholes" (Ehrenfels 1890; Wertheimer 1985). We understand the categorizing concepts as gestalt qualities and the group of components as organized by gestalt quality functioning as an abstract entity motivating the whole construction (Gogichev 2014).

In the process of realizing the gestalt quality some properties of the categorizing concept calling for conceptualization can be reified as a relation of the original category to a special category that will be termed as a specifying category representing one of culturally relevant ideas. As the result of the original category's specification subordinate level categories emerge located rather low in the graduated cognitive system.

The structures described by $\mathrm{G}$. Lakoff as subordinate categories make a very interesting field in terms of observing 
reasoning. Very often they are a result of infiltration of some qualities that exist only in the human mind. Many of them might be of "preconceptual" nature (G. Lakoff 1980), but a big part of them is constituted by special concepts or structures that motivate development of the conceptual system.

A thing being perceived is not conceptualized as it is seen, rather often it is included in complex structures requiring material to complete a gap in their construction and imposing its own limits on the whole group. As V.I. Abaev argued that "the differences in the world understanding are the very reason of how differently we cognize the same entity and vice versa.... None of entities that we perceive is isolated from our previous experience. In the process of comprehension it is included in various semantic complexes and takes its place in our ideology (Abaev 1995).

In this article we address the categorizing concepts as well as specifying categories and cognitive operations underlying the processes of conceptual structuring and examine idioms that subdivide the category of "human" in Ossetian language. The main objectives of the study are:

- registration of all idioms constituting the relevant subcategories in Ossetian;

- description of their properties corresponding to one of the categorizing concepts;

- definition of the type of the relation that the cognized entity has to the subcategory.

\section{Methodology}

The methods applied in the work are based on different mental structures analysis: conceptual analysis helps discover the quality of the categorizing concept underlying the subcategorization initializing process, describing the relevant subcategory structure allows to observe the way people cognize the perceived entity as a part of an already existing gestalt and operationalization clarifies the whole process of subcategorization including all relevant parts and relations between them.

\section{Categorizing Concepts}

The structures underlying extension of the conceptual system and building the subordinate categories are denoted here as categorizing concepts. The subcategories emerging as a result of interaction of a basic category and a categorizing concept are characterized by having a wide number of semantic properties. They are represented in the language e.g. by idioms, so classes formed by idioms can reveal some mechanisms of categorization. Denotation of idiom semantics expresses two or more properties originating from different conceptual sources one of which can be considered as categorical (of the basic category) and the others as properties of a categorizing concept, e.g. the idiom "spill the beans" has a categorical notion of "man" and additional qualities "reveal a secret".

In the literature metaphor or conceptual metaphor is considered as the main pattern of semantic organization of idioms (Lakoff \& Johnson 1980). To develop this account we grouped idioms that represent the basic domain in categories that subdivide the basic category. Such categories incorporate different properties of the categorizing concept and further specify the basic category on the subordinate level. These categories exhibit certain organizing properties: the category members cover several conceptual subtypes of the basic category and are linked together by the categorizing concept's structure. They can include different category members labeling a special quality.

\section{Specifying Categories}

In the process of completing a gestalt some properties of the categorizing concept can be only realized as a relation of the subject (basic or superordinate category) to special categories expressing different ideas with various types of relations to these classes. The kind of the relation of the basic category to the given object defines the way to one of the subcategories relevant in the conceptual system. The cognitive operation can be described as consisting of three components: subject (basic or superordinate category), relation and object (specifying category).

Subcategorization in Ossetian

(phraseological data taken from (Dzabity 2003)

The subcategory "intelligent man" in Ossetian is constituted by following elements:

Basic category (superordinate level) - human

Categorizing concept: Zond (Intelligence, Knowledge, Experience)

Resultung category (subordinate level) - zangin adaimug (intelligent man)

Actualized properties:

1. Availability of Intelligence (the category members represent a realization of the conceptual metaphor HEAD IS 
A CONTAINER OF INTELLIGENCE): uakhsdjytyl sar uyn (lit. the head is on the shoulders), afsaynug sar (lit. iron head), saray ahast uyn (lit. the head is complete).

2. Availability of the extreme degree of Intelligence (a part of the category members is structured as a metaphorical qualification of the component zond (intelligence): arttivug zond (lit. shining intelligence), zondy kuybar (lit. a lump of intelligence), zondy masyg (lit. a tower of intelligence); another part of this section with the meaning "an acute mind/person who knows everything" is based on the relation (to know) to the category "hardly understandable things" represented in the literal meaning of the idioms' components:

saryl sal huny is uyi zonyn - to know how many hairs are on one's head

zahhy byn zy is uyi zonyn - to know what under the ground is

3. Availabilty of the qualities' combination "intelligence-following social regulations" expressed by the literal meanings of the idioms adamy khar ambaryn (lit. hear people's voice), dzyhy radavinag na uyn (lit. smb. can not be placed in the mouth) denoting "to be intelligent, follow the rules of the society".

It has to be added that the concept "following social regulations" is also realized in the collocation guydynmarzan uaddar sag (lit. say guydynmarzan at least) in the category "someone who doesn't say hello to anybody" defined by the categorizing concept: salam zagyn (lit. say hello). The general meaning is motivated by the word guydynmarzan associated with the quality "a minimal unit of communication".

The categorizing concept "intelligence" in Ossetian implies among others labeling a relation of the subject (man) in terms of to know/not to know to a category "hardly understandable things" consisting of members like saryl sal huny is (haw many hairs are on the head) $и$ zahhy byn zy is (what is under the ground) to intensify the defined quality. The quality of the categorizing concept underlying this structure is INTELLIGENCE IS KNOWING EVERYTHING SECRET.

In the following subcategory another cognitive operation is realized signaling a relation of the basic category "man" the specifying category "impossible things":

Basic category (superordinate level) - human

Categorizing concept: sarandzinad (deftness, sharpness)

Resultung category (subordinate level) - saran adaimug (deft man)

1. Availability of Deftness: kuhyl sudzga (lit. something is burning in one's hands), tug fyzy (lit. somebody's blood is burning), ahsidga zarda (lit. boiling heart) (the category members represent a realization of the conceptual metaphor MASTERING A SKILL IS FIRE/BOILING);

2. Ability to achieve impossible (the concept of "impossible" is expressed by the literal meaning of the idioms' components):

anadon ranai don rauadzyn - be able to find water in a waterless place

dury guybynai don rauadzyn - be able to get water from a stone's stomach

garkaiy hunchy alasyn - be able to get through a small ring

bandanyl hurtuan kanyn - be able to put grain on a rope to dry

arvy karatty dar ssaryn - be able to find something even at the edge of the sky

sudziny byn ssaryn - be able to find under a needle

tarhus uardonyl ahsyn - be able to to catch a hare on a cart

3. Ability to keep one's head, to find a way out of all difficult situations (the relevant concept is expressed by the literal meaning of the idioms' components): the fat);

Byny amizyn zonyn ama ya asy kanyn dar zonyn (lit. to know to piss oneself and to wipe up); fiuma avnalan (catch

4. Ability to protect oneself (this part of the category employs a relation (be able to protect oneself from...) of the basic category 'man' to a specifying subcategory "dangerous things" represented by crow and wolf):

halon sa stag na hassy (lit. a crow can not take away a bone from them); to catch a hare on a cart dywwa biragy ia na bahardzysty (lit. two wolves can not eat them)

The categorizing concept "deftness, sharpness" is linked with specifying categories realizing the quality "impossible things" and "dangerous things" including respectively members anadon ranai don rauadzyn, dury guybynai don rauadzyn, garkaiy hunchy alasyn, bandanyl hurtuan kanyn, arvy karatty dar ssaryn, sudziny byn ssaryn, tarhus uardonyl ahsyn with the relation be able to to express the meaning "be able to do something impossible" and components halon and birag to define the relation of be able to protect oneself. The quality of the categorizing concept underlying this structure is DEFTNESS (SHARPNESS) IS AN ABILITY TO DO IMPOSSIBLE.

In the subcategory insatiable person the basic category man is among others specified in relation to the category "things that can not be taken away":

Basic category (superordinate level) - human 
Categorizing concept: anafsisdzinad (insatiability)

Resultung category (subordinate level) - anafsis adaimug (insatiable person)

1. Cruelty in the foreground of attention and insatiability in the background (this part of the category is structured by means of the propositional cognitive model birag $u$ agatyr (wolf is cruel) and exaggeration of the relevant quality by introducing the components ahhormag (hungry) and mardty (dead):

biragy myggag (lit. of the wolf's race); ahhormag birag (lit. hungry wolf); mardty birag (lit. wolf of dead);

2. Indication of insatiability with addition of the quality "disdain nothing" (this part of the category is based on the relation to the category "things that can not be taken away"):

kuydzy khushor uyn - to eat a dog's ears;

mard haradzhy zafhadta raftauyn - take off dead donkey's horseshoes;

kuydzy khus/ mardy archita/ mardy dzabyrta ralasyn - to take off a dog's ears/dead man's shoes; mardty khis haryn - to eat a dead man's bristle; khusta harynai tarsyn - to be afraid that somebody can eat one's ears;

3. Indication of the extreme degree of insatiability (this part of the category implies the conceptual metaphor INSATIABILITY IS A CONTAINER where the section container is represented by the components tung (gut), dzyppyta (pockets); defined by qualities stavd (thick), styr (big), anabyn (bottomless):

stavd tungdzhyn (lit. smb. has thick gut); styr dzyppyta (lit. big pockets); anabyn dzyppyta (lit. pottomless pockets);

4. Ability to be ready to do anything out of insatiability:

sudzin khusy lasyn (lit. put a needle through an ear); falloiyl mard uyn (lit. to be ready to die for one's goods);

The categorizing concept "insatiability" in Ossetian requires indication of a relation of the subject (man) to a category "things that can not be taken away" with members like kuydzy khushor uyn, mard haradzhy zafhadta raftauyn, kuydzy khus/ mardy archita/ mardy dzabyrta ralasyn, mardty khis haryn, khusta harynai tarsyn to add a different quality to the initial denotation. The type of the relation to the category can be described as disdain/not disdain. The property of the categorizing concept underlying this structure is INSATIABILITY IS DISDAINING NOTHING.

\section{Conclusion}

The inventory of specifying means represented by categorizing concepts and specifying categories functions as a conceptual structuring subsystem with each adding a different conceptual dimension of the initial category by means of various cognitive operations. The subcategories emerging as a result of these processes incorporate different qualities of the categorizing concept. These qualities define the semantic links between the category parts as well. The categorizing concepts represent gestalt qualities understood in this work as motivating structures and the categories as the body of gestalt.

While realizing one of the categorizing concept's properties a special structure appears as the base of a cognitive operation which can be designated as specifying categories functioning as the basic term of the cognitive process that can be termed as the subcategorization process. Regarding the above groups this process is defined as "subject relation (to) - object" where the relation component is indicated as to know, to be able to, to be able to resist and to disdain. The section of object is represented by categories "hardly understandable things", "impossible things" "dangerous things" and "things that can not be taken away" expressing the culturally relevant meaning.

\section{References}

Abaev, V.I. (1995). Yazyk kak ideologia i yazyk kak tekhnika. In Izbrannye trudy (V. 2.).Vladikavkaz: Ir.

von Ehrenfels, Christian (1890). Über Gestaltqualitäten. In Vierteljahrsschrift für wissenschaftliche Philosophie (Vol. 14.) (pp. 249-292). Leipzig.

Gogichev, Ch. (2011). Denotativny component semantiki idiom. In Economicheskie i gumanitarnye issledovania regionov Vol. 4. (pp. 102-107). Rostov.

Gogichev, Ch. (2014). Gestalt kak organizuiushi component semantiki idiom. In Economicheskie i gumanitarnye issledovania regionov Vol. 1. (pp. 63-68). Rostov.

Dzabity, Z.T. (2003). Iron avzagy fraseologion dzyrduat. Zhinval: Ir.

Lakoff, George \& Mark Johnson (1980) Metaphors We Live By. Chicago: University of Chicago Press.

Lakoff, G. (1987). Women, fire, and dangerous things. What categories reveal about the Mind. Chikago-London.

Talmy, L. (2000). Toward a Cognitive Semantics. Cambridge MA: The MIT Press.

Wertheimer, Max. (1985). Über Gestalttheorie. In Gestalt Theory (Vol. 7.), No. 2, (pp. 99-120). Opladen: Westdeutscher Verlag. 